\title{
Evolução, mudanças de uso e apropriação de espaços públicos em áreas centrais urbanas
}

\author{
Evolution, changes of use and appropriation of public \\ spaces in central urban areas
}

\section{Guilhermina Castro Silva \\ Wilza Gomes Reis Lopes \\ J oão Batista Lopes}

\section{Resumo \\ A}

s praças são locais de convívio social e de encontro com a natureza, que podem contribuir para a formação e agregação da sociedade, representando espaços importantes para manifestações culturais, sociais e políticas. O presente trabalho analia as mudanças de uso ocorridas em praças centrais urbanas, tendo como enfoque a Praça João Luis Ferreira, em Teresina, Piauí, bem como avaliar os benefícios e problemas causados pelas atividades exercidas no local, na perspectiva de que as informações geradas possam contribuir para definição de políticas públicas para ocupação desses espaços públicos. Na pesquisa, utilizou-se abordagem qualitativa e quantitativa, envolvendo análise de documentos históricos, registro fotográfico, entrevista e aplicação de questionários, visando a identificar diferentes tipos de usuários, as atividades desenvolvidas e os horários mais utilizados. Também, foi realizado um diagnóstico da situação geral da praça, a partir de observação direta, com identificação, descrição e análise dos equipamentos existentes, para avaliar se o ambiente atendia aos requisitos de conforto do usuário e de sua conservação. Com a reforma ocorrida 2000, que pretendia revitalizar o uso da praça pela população,

Guilhermina Castro Silva Pós-Graduação em Desenvolvimento e Meio Ambiente Universidade Federal do Piaú Campus Universitário Ministro Petrônio Portella, Ininga Teresina - PI - Brasi CEP 64049-550 Tel.: (86) 3215-5525 E-mail:

guilherminacastro@hotmail.com

Wilza Gomes Reis Lopes Departamento de Construção Civil e Arquitetura

Universidade Federal do Piauí Campus Universitário Ministro Petrônio Portella, Ininga, Bloco CT Teresina - PI - Brasil CEP 64049-550 Tel.: (86) 3215-5725

E-mail: izalopes@uol.com.br

J oão Batista Lopes Departamento de Zootecnia Universidade Federal do Piauí Campus Universitário da Socopo, Ininga

Teresina - PI - Brasil CEP 64049-555

Tel : (86) 3215-5750

E-mail: lopesjb@pesquisador.cnpq.br

Recebido em 10/05/10

Aceito em 31/07/11 inseriu-se um ponto de ônibus que atraiu o comércio informal, resultando em novos tipos de apropriação do espaço. Concluiu-se que os equipamentos do espaço estão medianamente conservados e a ocupação da praça está caracterizada, principalmente, pelas atividades de circulação de pedestres, lazer passivo e comércio informal.

Palavras-chave: Espaço público. Praça. Apropriação. Teresina. Piauí.

\section{Abstract}

Squares are places for conviviality and contact with the nature, which can contribute to forming and congregating society, representing important spaces for cultural, social and political manifestations. This article examines changes that have happened in the use of squares in central urban areas, focusing on the João Luis Ferreira Square, in Teresina, Piauí, and also evaluates the benefits and problems caused by the activities that take place on that square. It is expected that the information produced in this investigation can contribute to the process of establishing public policies for the occupation of those public spaces. The study used qualitative and quantitative data, including historical document analysis, photographs, interviews and questionnaires. Those data were used to identify the different types of users, their activities and the most popular times of use of the square. In addition, an analysis of the general situation of the square was undertaken, including the identification, description and analysis of the equipment in order to evaluate whether the environment meets some requirements of maintenance and user comfort. The refurbishment project, carried out in in 2000 to revitalize the use of the square by the population, inintroduced a bus stop, which attracted informal traders, resulting in new types of space appropriation. The results indicated that the equipment has been fairly well-maintained and that the occupation of the square is characterized mainly by activities of circulation of pedestrians, passive leisure and informal commerce.

Keywords: Public space. Square. Appropriation. Teresina. Piauí. 


\section{Introdução}

A partir do movimento migratório simbolizado pelo abandono das áreas rurais, teve-se como reflexo o crescimento da população urbana de forma desordenada. Na mesma proporção, ocorreu o crescimento de áreas edificadas nas cidades, caracterizadas pelos espaços destinados a habitação, comércio, serviços, indústrias e os considerados livres, tendo estes últimos a função de suprir as necessidades básicas de convivência, recreação e lazer.

Os espaços livres são considerados todas as áreas sem edificação, como as destinadas à circulação, representadas pelas ruas, vielas, avenidas, corredores externos, rotatórias, pátios e quintais, além das áreas utilizadas para recreação, lazer e estar, como as praças e os parques. Tais espaços contribuem para a melhoria da qualidade no ambiente urbano, favorecendo, segundo Cunha (2002), a funcionalidade e a melhoria das condições ambientais e sanitárias, e também proporcionam condições de convívio e lazer, além de atributos estéticos ao lugar. São considerados como pontos de encontro, configurando-se como locais onde as pessoas têm livre acesso, podendo exercer diversas funções. As áreas públicas centrais apresentam, em sua maioria, características comuns de uso, como acessibilidade, transparência, conforto e permanência.

As praças são locais de convívio social e convívio com a natureza, que podem contribuir para a formação e agregação da sociedade, e representam espaços importantes para manifestações culturais, sociais e políticas. Elas nasceram de necessidades de espaços para abrigar as festividades, encontros, atividades de troca, tratando-se de lugares de fácil acesso para a sociedade realizar as mais variadas funções, como ver e ser visto, para comprar e fazer negócio, fazer política e passear.

A cidade de Teresina, idealizada pelo Conselheiro Saraiva, na época Presidente da Província do Piauí, foi planejada em 1852, para ser a capital do Piauí, estado do Nordeste do Brasil, em substituição à cidade de Oeiras, sua primeira capital. Atualmente, a cidade tem em seu centro histórico um total de sete praças: Marechal Deodoro da Fonseca, Rio Branco, João Luis Ferreira, Landri Sales, Praça Pedro II, da Liberdade e Saraiva.

A Praça João Luis Ferreira está inserta num entorno caracterizado pela concentração de atividades comerciais e serviços, apresentando intenso fluxo de veículos. Esse espaço apresenta também uma forte presença do comércio informal, que foi atraído pelo fluxo de pessoas que passam por ele.

Este trabalho foi desenvolvido visando estudar as mudanças de uso ocorridas em praças centrais urbanas, tendo como enfoque a Praça João Luis Ferreira, em Teresina, Piauí, bem como avaliar os benefícios e/ou problemas causados pelas atividades exercidas no local, na perspectiva de que as informações geradas possam contribuir para a definição de políticas públicas para a ocupação desses espaços livres.

\section{Cidades, espaços públicos e praças}

A cidade apresenta uma organização espacial em que a utilização do solo tem usos diversos, com áreas destinadas à concentração de atividades comerciais, serviços e gestão, zonas industriais, residenciais e espaços para circulação e lazer. Para Lefèbvre (2001), as cidades são centros da vida social e política, local onde se acumulam riquezas, conhecimento, tecnologias, obras de arte e monumentos.

Macedo (1986) afirma que os espaços livres de edificações surgem, junto às áreas edificadas, em decorrência da criação de sistemas viários, de recuos obrigatórios nos lotes, formando poços de iluminação, pátios, quintais, bem como em decorrência da exigência de áreas para recreação e estar. Esses espaços têm como funções melhorar a qualidade ambiental na cidade e contribuir para o fortalecimento da identidade local, com a delimitação das áreas urbanizáveis. O espaço livre público surgiu nas cidades gregas e romanas, onde o centro da cidade se apegava a um espaço vazio, tendo a Ágora e o Fórum como referências.

Nesse contexto, Benévolo (2003) afirma que a função social do espaço livre origina-se diretamente da Ágora, que era um espaço aberto em que ocorriam os encontros, conversas e discussões em setores importantes, como do direito, governo, comércio, indústria, religião, sociabilidade. Assim, não é de se admirar que continuasse a ganhar a atenção da acrópole até se tornar o elemento mais vital e distinto da cidade. A Ágora era um espaço comum, centralizado, onde se debatiam os problemas de interesse geral. De acordo com Mumford (1998), trata-se de um espaço que representava o símbolo da liberdade e também o centro dinâmico da cidade grega, um “local de assembleia”, com a finalidade de reunião.

A urbanização e o crescimento da população acarretam, para a cidade, uma série de problemas 
sociais (moradia, saúde, educação, alimentação, lazer, etc.) e ambientais (desmatamento, impermeabilização do solo, destruição ou modificação dos ecossistemas, alterações climáticas, poluição ambiental), necessitando de um planejamento para reduzir tais impactos. Para Barros e Virgílio (2003), o processo de urbanização tem-se caracterizado pela substituição do ecossistema natural, por um meio completamente adverso, em que o homem o organiza segundo suas necessidades de sobrevivência e o poder que exerce sobre esse espaço.

Os espaços livres podem contribuir para a melhoria da habitabilidade do ambiente urbano, pois possibilitam, na visão de Oliveira e Mascaró (2007, p. 60), “[...] o acontecimento de práticas sociais momentos de lazer, encontros ao ar livre e manifestações de vida urbana e comunitária.”. Além disso, a partir da vegetação existente, influenciam “[...] no microclima mediante a amenização da temperatura, o aumento da umidade relativa do ar e a absorção de poluentes, além de incrementar a biodiversidade.”.

As praças, um dos mais característicos exemplos de espaços livres, são unidades urbanísticas fundamentais para a vida urbana, configurando-se como locais para a prática de lazer passivo e ativo, além de servirem ao encontro e à convivência das pessoas e às atividades culturais e cívicas. Têm presença marcante na composição das cidades, levando-se em consideração sua diversidade e seu uso pela população, representando importantes elementos, tanto históricos como culturais. Marx (1980) refere-se à praça como logradouro público por excelência, que deve sua existência, sobretudo, aos adros de nossas igrejas, tendo surgido entre nós para reunião de gente e atividades diversas, diante de capelas ou igrejas.

No século XIX e até meados do século XX, as praças tinham grande importância para a vida citadina, funcionando como local de lazer e sendo o centro dos acontecimentos e novidades que ocorriam na cidade. Lima (2001) afirma que, ao longo dos tempos, as praças representavam o lugar de encontro, de comunicação, de trocas de mercadorias, de festas populares e de manifestações políticas, estando também associada à ideia de centro da cidade ou do bairro, locais para onde convergem e se concentram seus habitantes. Os usos e funções desses espaços foram modificando-se e adequando-se às mudanças e às necessidades da sociedade.

Para Macedo (1995, p. 24), a vida útil de determinado espaço livre urbano está “[...] diretamente vinculada à possibilidade constante de apropriação que este permite ao seu público usuário [...]”. Alves, Lopes e Sousa (2004) afirmam que, quando há falta de identidade entre comunidade e o espaço livre proposto, quando o projeto contempla estruturas que não se relacionam com as aspirações da população local, esses ambientes tornam-se ociosos e abandonados. Isso acaba acontecendo nas praças centrais das cidades, onde há pouca ou nenhuma residência no entorno e o centro urbano é caracterizado pela atividade comercial.

Abidin et al. (2010) definiram que as características que atraem os usuários para as praças são: localização, instalação e serviços, características do espaço, atividades opcionais, paisagem, conexão entre as pessoas e seu entorno, relação entre o contexto social e cultural do espaço público e acessibilidade.

\section{Procedimentos metodológicos}

Realizou-se pesquisa documental que abordou a história de Teresina e da Praça João Luis Ferreira. $\mathrm{O}$ resgate histórico foi baseado nos antecedentes da praça, os quais se encontram vinculados ao processo de evolução da cidade, apresentando as transformações na estruturação, implantação e uso desse espaço. Dessa forma, foi realizado levantamento da memória do projeto e da construção da praça por meio de entrevistas, artigos de jornais, fotografias e análise dos projetos arquitetônicos de revitalização.

Para diagnosticar a situação geral do espaço realizou-se, a partir de observação direta, levantamento, descrição e análise qualitativa dos equipamentos e mobiliários urbanos existentes na praça, considerando-se quantidade, disposição no espaço, conservação e tipo de material utilizado. Para a avaliação qualitativa desses equipamentos e mobiliários, foi utilizado o método de De Angelis, Castro e DE Angelis Neto (2004), que atribui valores de 0,0 a 4,0 aos itens existentes na praça, na seguinte escala:
(a) 0 a 0,4, péssimo;
(b) 0,5 a 1,4 , ruim;
(c) 1,5 a 2,4, regular;
(d) 2,5 a 3,4, bom; e
(e) 3,5 a 4,0, ótimo.

A avaliação foi realizada pelos pesquisadores considerando o conforto, a conservação e a distribuição dos equipamentos e mobiliários. Esses dados ajudaram a avaliar se o ambiente atende aos requisitos de conforto do usuário e aos aspectos ligados à conservação. 
Com a finalidade de identificar os diferentes tipos de usuários, as atividades realizadas por eles e os horários mais utilizados, desenvolveu-se mapeamento comportamental baseado em Pinheiro, Elali e Fernandes (2008), com a utilização de planta baixa esquemática da praça, em que se identificavam os espaços preferidos e as atividades desenvolvidas, permitindo ao pesquisador melhor compreensão do uso e funcionamento do ambiente estudado.

A observação foi realizada durante três meses, abrangendo três dias consecutivos de coleta, e intervalo de dois dias para a análise dos dados. Dessa forma, todos os dias da semana e os fins de semana foram englobados, com exceção dos dias atípicos, como feriados. Para cada período de coleta, foram seguidos os seguintes procedimentos:

(a) no primeiro dia, as observações ocorreram pela manhã, entre 7h30 e 12h00;

(b) no segundo dia, foram realizadas à tarde, das $12 \mathrm{~h} 00$ às $16 \mathrm{~h} 00$; e

(c) no terceiro dia, deram-se das $16 \mathrm{~h} 00$ às $20 \mathrm{~h} 00$.

No total, foram realizadas 54 observações, com 18 dias para cada período.

Para complementar as observações, foram aplicados 40 questionários aos usuários da praça, de forma aleatória, em diversos horários durante o dia, enfocando a frequência de uso e os tipos de atividades realizados na praça. Realizou-se, ainda, registro fotográfico durante todo o processo de coleta, o que permitiu avaliações posteriores.

\section{Resultados}

\section{Teresina e a evolução da Praça J oão Luis Ferreira}

Teresina está situada à margem direita do rio Parnaíba, sendo banhada também pelo rio Poti, apresentando a posição geográfica de 55'12” de latitude sul e longitude oeste de $42^{\circ} 48$ ' 42 ”. O traçado do plano da cidade de Teresina foi estruturado a partir de um rígido formato geométrico, que lembra um tabuleiro de xadrez, com suas ruas alinhadas, quarteirões pequenos e um grande largo circundado por prédios administrativos e religiosos. Suas ruas paralelas partiam “[...] do rio Parnaíba, a Oeste, em direção ao rio Poti, contendo um espaço urbano delimitado por dezoito quadras no sentido norte-sul e doze no sentido leste-oeste [...]” (LIMA, 1996, p. 18).

Desde seu traçado original, já tinham sido destinados quarteirões para a construção de praças, em sua grande maioria em terrenos baldios, com nenhuma ou com poucas benfeitorias, sem urbanização, como também era a condição da própria cidade naquela época (LIMA, 2001). Ao longo dos anos, os gestores municipais mostraram preocupação com as praças, como demonstra o relatório de atividades do prefeito Lindolfo do Rego Monteiro, referente ao exercício de 1941, em que destaca a importância dessas áreas para a cidade de Teresina, devido às condições do clima local, e ainda aponta a necessidade da abertura de novas praças e da conservação e melhoria das existentes (MONTEIRO, 1943).

A Praça João Luis Ferreira, em 1905, não fazia parte do traçado do Conselheiro Saraiva, tendo surgido a partir de uma desapropriação de terrenos, em que foi doada à Prefeitura a área de um quarteirão para sua construção. Inicialmente, esse espaço foi denominado Praça da República. Sua construção se deu no mandato do prefeito Anfrísio Lobão (1925-1929), que, para homenagear o exgovernador do Piauí, João Luis Ferreira (19201924), falecido em 1927, alterou o nome para Praça João Luis Ferreira. Em 1930, a praça foi remodelada, envolvendo meios-fios, calçamento, passeio e iluminação interna, e a conclusão da reforma ocorreu em 1932 (TITO FILHO, 1978).

Seu traçado é considerado clássico romântico, composto de dois eixos principais marcados pelos passeios largos e simétricos, correspondendo a uma área total de 5.030,07 $\mathrm{m}^{2}$. Macedo (1999, p. 23) define o traçado clássico como um espaço

\section{[...] retratado a partir de um parcelamento geométrico do solo, favorecendo-se a criação de pisos e caminhos estruturados por eixos, que convergem para um ponto principal, conectando-o aos diversos acessos.}

Dobal (1992, p. 21) descrevia a praça como sendo “[...] das crianças, dos namorados e das árvores que têm um breve outono, quando desfolham antes da floração [...]”. Seu entorno agrupava residências de famílias muito tradicionais, sendo, portanto, um foco de convivência e diversão social, conforme a descrição de uma moradora do entorno, na década de 1930: 
A praça era toda cercada de figueira e o centro arborizado. Na gestão do meu pai (Anfrísio Lobão) ele encomendou essas plantas. No centro da praça, tinha um tanque que servia para aguar as plantas $e$ um coreto onde os políticos faziam seus comícios. No final da década de 1960, o tanque foi coberto e o coreto foi levado para a Praça Deodoro ${ }^{1}$.

Na década de 1940 e no início de 1950, a praça era utilizada de várias formas. Carvalho (2005, p. 52) comenta que a praça “[...] foi o lugar preferido para a realização das poucas festas regionais, fora o Carnaval, que ocorriam em Teresina. O São João era uma delas, senão a principal [...]”. O autor descreve, ainda, como essa festa era importante para a cidade, relatando que, “[...] não era um São João simples, só de fogueiras, do casamento matuto, mas uma festa popular já estilizada à maneira da época, sempre em benefício de obras sociais” (CARVALHO, 2005, p. 52).

No final da década de 1950, os jornais da época enfatizavam a realização da reforma, com a inclusão dos equipamentos para recreação infantil, noticiando que

\section{[...] também estão em andamento os trabalhos da Praça João Luiz Ferreira, onde ficará localizado um parque infantil, fato que também impõe aplauso à prefeitura, pois preencherá uma lacuna na vida da cidade (PRAÇAS, 1957, p. 2).}

Crianças brincavam na época utilizando o espaço e os brinquedos infantis existentes na Praça João Luis Ferreira (Figura 1). A introdução do lazer ativo, abrangendo quadras poliesportivas e brinquedos para crianças, segundo Robba e Macedo (2002), é inerente às características da praça moderna, em consonância com as demandas da sociedade de então.

A praça, nessa época, significava um espaço importante e tinha muitas formas de entretenimento, em que as famílias podiam se reunir, levando as crianças para se divertir no parque infantil, enquanto os jovens aproveitavam para se encontrar e namorar. O uso do espaço refletia o tipo de ocupação de seu entorno, tipicamente residencial. Essa situação reflete a afirmação de Lima (2001) ao destacar que as praças representavam o lugar de encontro, de comunicação, de manifestações populares e políticas.
No entorno da Praça João Luís Ferreira, em janeiro de 1950, segundo Meneses e Bezerra (2005), foi inaugurado o Instituto de Aposentadoria e Pensões dos Comerciários (IAPC). Foi a primeira construção com oito andares da cidade, sendo durante anos o único edifício da então pequena cidade, representando um marco visual e histórico para Teresina e exemplo de edifício de uso não residencial em volta da praça. Considerado como arranha-céu para a época, o edifício tinha como finalidade "[...] abrigar a sede e o ambulatório do Instituto dos Comerciários [...]” (MENESES; BEZERRA, 2005, p. 57). Em imagem da década de 1960 (Figura 2) é possível visualizar, ao fundo, o edifício IAPC contrapondo-se ao casario residencial existente no entorno e a Praça João Luís Ferreira, destacando-se em primeiro plano o playground.

Com o passar dos anos, o parque infantil foi desativado, e a atividade comercial cresceu no centro da cidade, ocupando também o entorno da praça, fazendo com que o local se tornasse um espaço diferente daquele existente nas décadas de 1950 e 1960. Assim, a praça deixou de ser um espaço das famílias para ser um local mais ativo e de passagem, devido ao fluxo de pessoas e ao comércio informal, que, aos poucos, ocupou o espaço da praça (Figura 3), refletindo o contexto social, político e econômico de Teresina naquela época, o que se encontra de acordo com Leitão (2002), quando afirma que a função dos espaços livres públicos é definida pelo modo como cada sociedade expressa sua vida, variando em função das mudanças sociais e históricas vivenciadas ao longo do tempo, como transformações pela “globalização” da economia e da comunicação, tendo, consequentemente, reflexos na estrutura física e na ambiência urbana.

\footnotetext{
1 Informação verbal obtida com a Sra. Maria Heloísa Lobão Sampaio, filha do ex-prefeito Anfrísio Lobão, em entrevista concedida a autora, em setembro de 2008.
} 

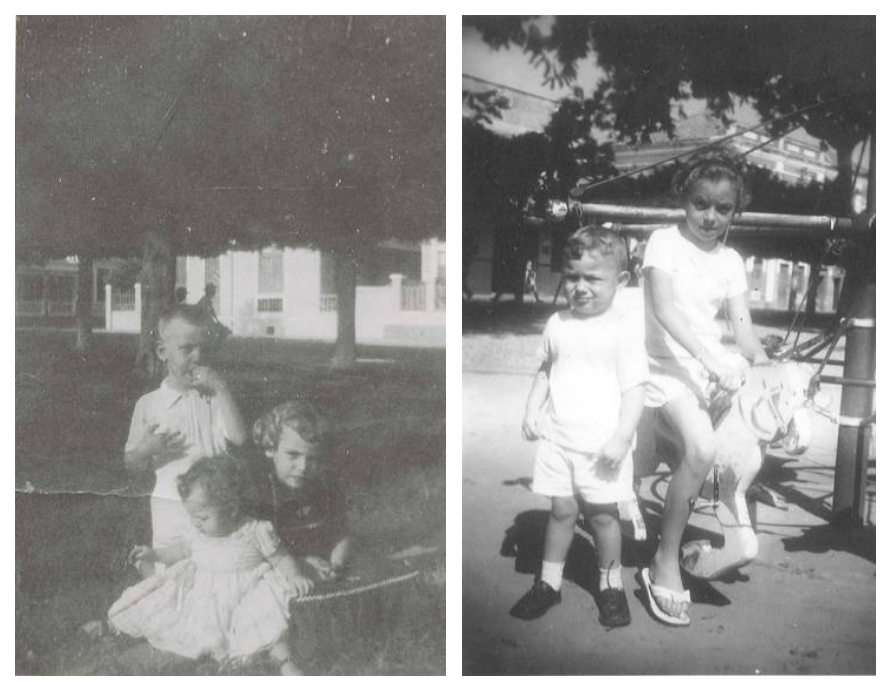

Figura 1 - Crianças brincando no parque da Praça J oão Luis Ferreira no final da década de 1950 Fonte: acervo particular de Adriana Fortes.



Figura 2 - Praça J oão Luís Ferreira e o prédio do IAPC na década de 1960

Fonte: acervo Espaço Cultural São Francisco.


Figura 3 - Praça J oão Luis Ferreira na década de (a) 1990 e em (b) 2009

Fonte: (a) acervo Casa da Cultura de Teresina e (b) ) foto de Guilhermina Castro Silva tirada em 2009. 
Em 2000, a praça foi reformada com o objetivo de resgatar alguns elementos arquitetônicos, como postes e bancos, que marcaram sua identidade. Com a reforma, foram colocados dois pontos de ônibus, que atraíram, ainda mais, o comércio informal, devido à concentração de pessoas. Além desse tipo de comércio, a Prefeitura Municipal de Teresina permitiu a realização de feiras mensais, com a instalação de boxes metálicos. O local se tornou um espaço com novas funções, a partir da presença do comércio informal, exercido tanto por comerciantes que permanecem o dia todo como por aqueles que circulam por outros espaços, a exemplo dos vendedores de feijão verde e de frutas, que vendem seus produtos com o auxílio de um carrinho de mão (Figura 4).

Com isso, a praça deixou de ser um local com prioridade de interação social para se tornar um local caracterizado pela atividade comercial. Segundo Robba e Macedo (2002), alguns projetos oficializaram a apropriação informal nas praças por feiras livres e camelôs.

A mudança de usos em espaços urbanos do Brasil, em função das atividades do entorno, é descrita em outros locais, como nas Praças Tubal Vilela, Adolfo Fonseca e Clarimundo Carneiro, em Uberlândia, Minas Gerais (BERTOLUCCI, 2003), e Praça Ernesto Tochetto, em Passo Fundo, Rio Grande do Sul (MELO; ROMANINI, 2008). Fora do Brasil, Low $(1998,2000)$ estudou a história, a cultura e o simbolismo físico e espacial da Praça da Cultura e da Praça Parque Central em São José (Costa Rica), e Abidin et al. (2010) estudaram as características e a integração social na Putra Square, em Putrajaya (Malásia).

\section{Descrição da Praça J oão Luis Ferreira}

Na Tabela 1, estão listados os equipamentos e mobiliários existentes na praça, com descrição de seu estado atual de conservação e a nota atribuída ao conforto e sua manutenção.

A praça apresenta conservação mediana em relação aos equipamentos e mobiliário urbano, sendo alguns considerados ótimos pela utilização e quantidade no espaço. As placas de sinalização estão distribuídas ao redor da praça, informando nomes de ruas, sinalização de trânsito, tendo fácil visualização pelos transeuntes. Contudo, constatou-se a falta de placa com o nome da praça, o que contribuiria para a identificação do espaço, principalmente para os visitantes da cidade.

As três bancas de revistas e o bicicletário estão distribuídos ao redor da praça (Figura 5). No domingo, apenas uma banca fica aberta pela manhã, sendo referência para os antigos clientes que moram no centro. O bicicletário é bastante utilizado, visto que, na cidade de Teresina, é grande a participação do uso de bicicletas para os deslocamentos diários, representando, aproximadamente, $11,8 \%$ do total (SANTOS, 2008).

Os pontos de ônibus existentes no local têm modelo padronizado pela Prefeitura Municipal de Teresina, embora não sejam adequados ao clima do local, por não protegerem os usuários da radiação solar e da chuva (Figura 6), mas são muito utilizados devido à grande área sombreada existente na praça.
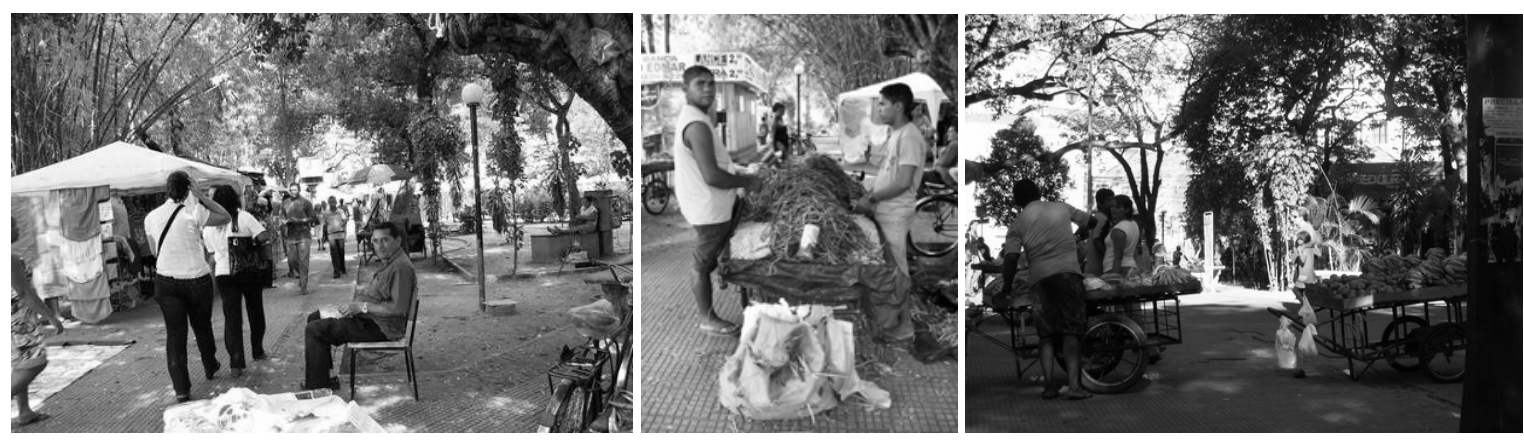

Figura 4 - Feira do microprodutor e vendedores de feijão verde e frutas na Praça J oão Luis Ferreira 
Tabela 1 - Resumo do levantamento do mobiliário e equipamentos existentes na área da Praça J oão Luís Ferreira

\begin{tabular}{llc}
\hline \multicolumn{1}{c}{ EQUIPAMENTOS } & \multicolumn{1}{c}{ DESCRIÇÃO } & NOTA $^{*}$ \\
\hline Banca de revista & 03 de metal e forro PVC & 3,5 \\
Bicicletário & 01 com capacidade para 15 bicicletas & 3,5 \\
Placas de sinalização & 06 com nomenclatura de ruas & \\
& 08 com sinalização de trânsito & 3,5 \\
Quiosque de & 02 pontos de venda de sorvete & 3,0 \\
alimentação & 10 orelhões do tipo padrão, de fibra de vidro, distribuídos & \\
Telefone público & em unidade e em dupla & 3,0 \\
Ponto de ônibus & 02 estruturas de metal com cobertura de polipropileno & 3,0 \\
Bancos & 44 de concreto sem encosto com apoios adornados, estando & 3,0 \\
Iluminação baixa & 01 quebrado & \\
Lixeiras & 06 postes com 2 m de altura (01 lâmpada) & 2,5 \\
& 01 contêiner & 2,5 \\
Obra de arte & 03 de metal com suporte & 2,0 \\
\hline
\end{tabular}

Nota: * de acordo com De Angelis et al. (2004).
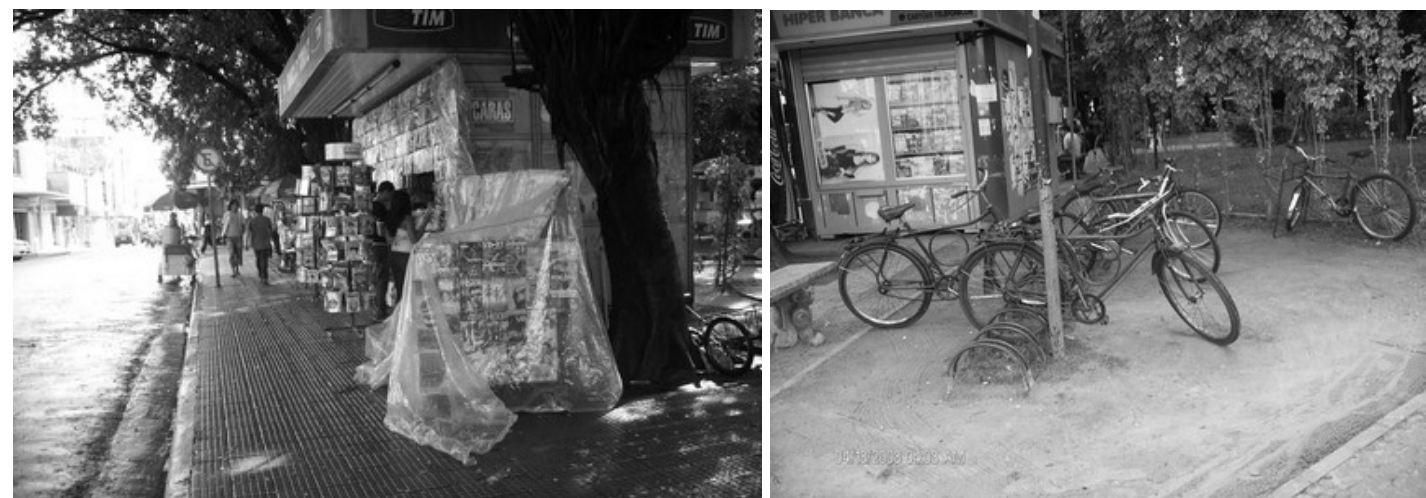

Figura 5 - Bancas de revistas e bicicletário na Praça J oão Luis Ferreira
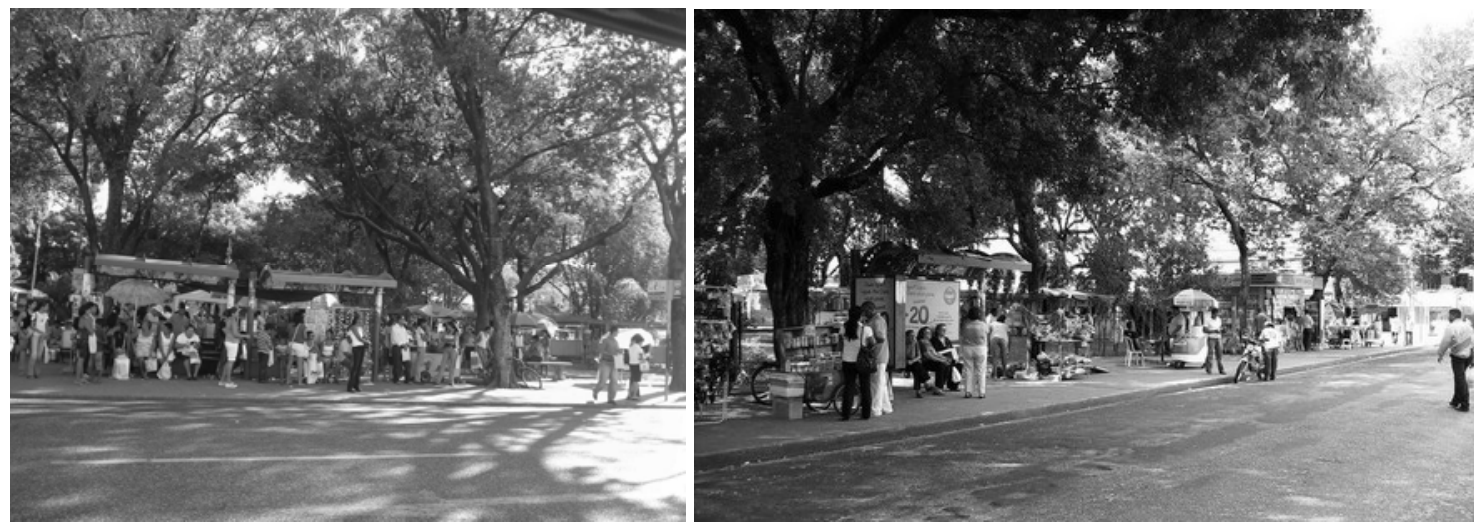

Figura 6 - Pontos de ônibus na Praça J oão Luis Ferreira

204 Silva, G. C.; Lopes, W. G. R.; Lopes, J. B. 

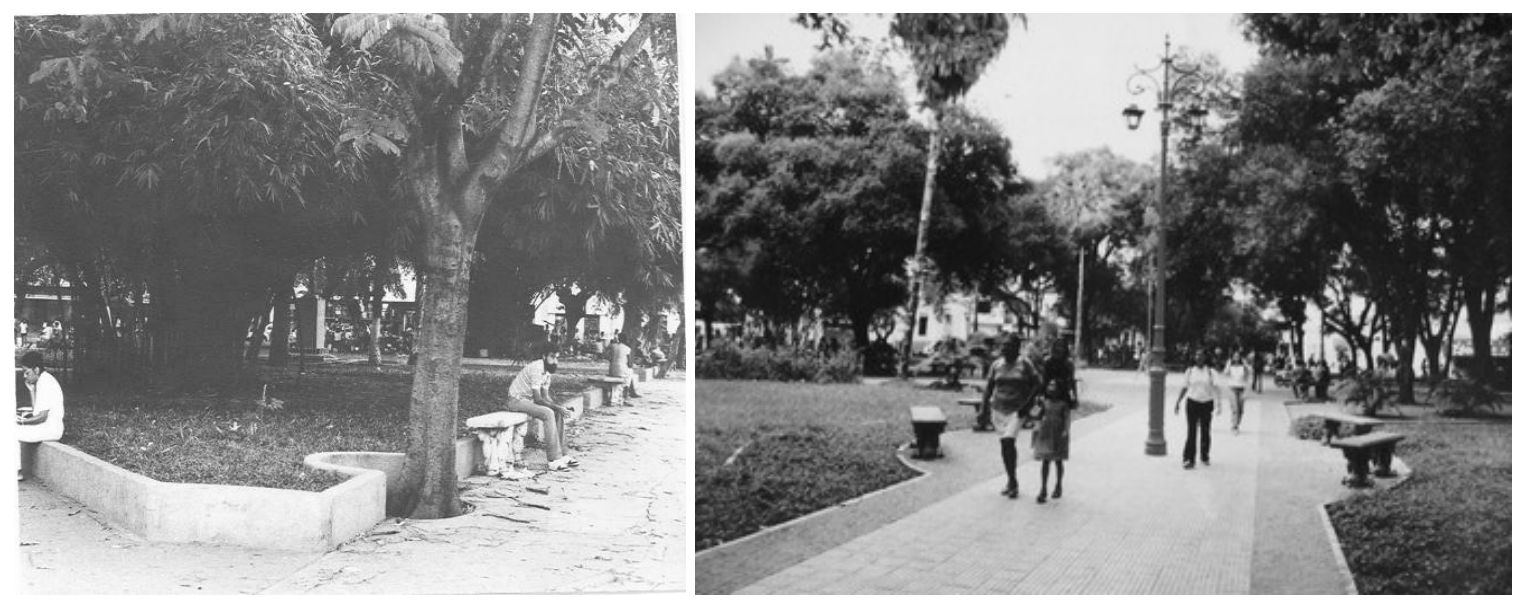

Figura 7 - Praça J oão Luis Ferreira na década de (a) $\mathbf{1 9 8 0}$ (a) e após a reforma, em (b) 2000

Fonte: (a) acervo Casa da Cultura de Teresina e (b) Teresina (2002, p. 3).

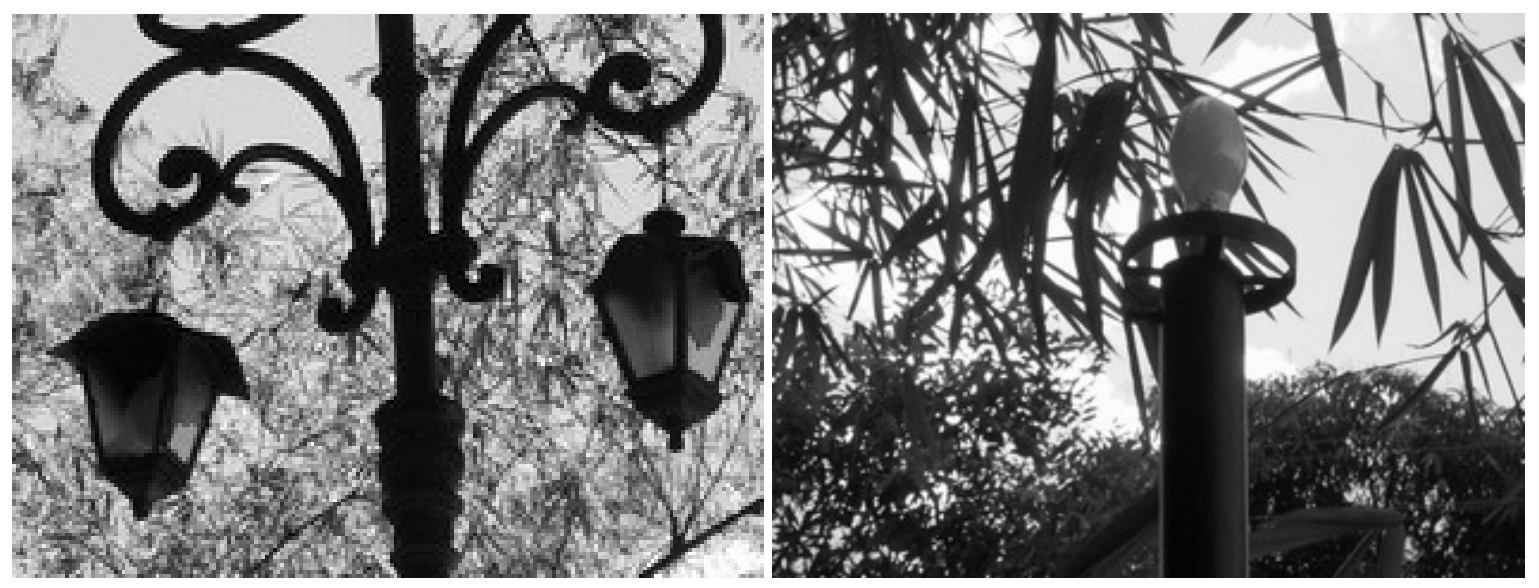

Figura 8 - Luminárias com lâmpadas quebradas na Praça J oão Luis Ferreira

Na década de 1980, a praça possuía canteiros com aproximadamente $0,50 \mathrm{~m}$ de altura, que foram rebaixados, ficando no mesmo nível do piso, que foi reformado com pedra portuguesa na cor vermelha, contornando todos os passeios e ladrilho hidráulico (Figura 7). Atualmente, o piso se encontra danificado devido à colocação dos boxes metálicos da feira do microprodutor.

Os postes de iluminação antigos foram reaproveitados e pintados na cor laranja, para realçar sua estética em meio à massa arbórea, tendo sido incluídas outras luminárias de globo e uma lâmpada. Dos 28 postes existentes, no período da pesquisa, somente cinco estavam funcionando, estando o restante quebrado ou com as lâmpadas queimadas (Figura 8).

A praça tem quantidade suficiente de lixeiras espalhadas em sua área; duas de polietileno estão quebradas. As atividades comerciais informais não ajudam na limpeza do espaço e, para completar, os usuários jogam lixo na praça (Figura 9).
As estátuas, bustos e monumentos são obras de valor cultural que representam a memória da história da cidade e dos "filhos ilustres", mas com o tempo essas homenagens passam a ser despercebidas pela população. A estátua do pediatra Helvídio de Aguiar é a única na praça e apresenta sinais de vandalismo, sendo utilizada como local para anexar cartazes (Figura 9).

As obras de arte que estão insertas nos espaços públicos precisam ser respeitadas em projetos de requalificação urbana por fazerem "[...] parte importante da memória coletiva da cidade [...]". Esses objetos tanto podem "[...] contribuir para a composição da paisagem quanto podem ajudar a descaracterizá-la [...]” (LEITÃO, 2002, p. 70). Isso depende da memória da sociedade, do valor histórico e cultural que essas pessoas homenageadas têm na atualidade.

A Praça constitui elemento importante para a preservação da identidade cultural das cidades, não devendo, segundo De Angelis et al. (2005, p. 633), 
[...] ser vista somente a partir das suas funções estética, de lazer e ecológica. Ela precisa ser entendida enquanto estrutura que acompanhou (aquelas antigas) $e$ acompanha (praças novas) os processos de transformação da sociedade local [...].

As praças centrais devem exercer a função de interação e convívio social sem barreiras físicas, tornando-se um espaço atrativo e convidativo para o uso pela população.

Os equipamentos existentes na Praça João Luis Ferreira estão medianamente conservados, estando alguns quebrados ou danificados, devido à ação de vândalos. A iluminação, que é essencial nesses espaços, está precária, com lâmpadas queimadas ou quebradas, restringindo a permanência dos usuários à noite. A resolução desses problemas contribuiria para uma maior apropriação do local pelos habitantes da cidade, pois a adequação dos equipamentos e mobiliários urbanos favorece a permanência do usuário na praça. Segundo Reis e Lay (2006), o modo de conservação e manutenção de equipamentos dos espaços públicos indica o uso, a mensuração, as percepções, as atitudes, os comportamentos e as avaliações desses espaços por seus usuários.

A Praça João Luis Ferreira segue a tendência natural das praças centrais das grandes cidades, deixando de funcionar como local de lazer e centro dos acontecimentos e adequando-se às mudanças e às necessidades da sociedade. Essa constatação está em consonância com as observações de Santos (2007), ao relatar que as praças passaram a se constituir em um fragmento a mais dentro da malha urbana com 0 advento de formas alternativas de lazer e de novos locais para estabelecimento do comércio, associados ao descaso do poder público quanto à manutenção desses espaços.

\section{Entorno da Praça J oão Luis Ferreira}

Prédios históricos, da primeira metade do século $\mathrm{XX}$, podem ser vistos ao redor da praça, bem como antigas residências, que eram caracterizadas por casas com varandas e sobrado que foram adaptadas para uso comercial.

Até o início da década de 1990, a praça foi utilizada pelos alunos como uma extensão dos colégios localizados em frente à praça. Atualmente, o entorno da praça é comercial, com lojas, lanchonetes, estacionamento, clínicas e escritórios (Figura 10).

As casas residenciais deram lugar aos pontos comerciais, modificando a paisagem e o entorno da praça, descaracterizando, assim, a arquitetura original das casas (Figura 11). Em consequência, a ocupação da praça foi-se adequando à nova realidade, fato comum na maioria de nossas cidades, onde os centros urbanos, que representavam o "coração das cidades", perderam sua vitalidade, pois, como relatado por Silva (2006, p. 146),

[...] com a expansão da cidade, a classe burguesa começou a perder o interesse em habitá-los, iniciando-se o processo de 'esvaziamento' da função residencial da área central [...].

Entretanto, outras residências não foram totalmente descaracterizadas, pois os proprietários tiveram a preocupação de preservar parte da arquitetura original (Figura 12).

Fora as atividades comerciais, existem, ainda, uma Igreja Evangélica e o antigo prédio do Instituto de Aposentadoria e Pensões dos Comerciários, estando esse último em fase de reforma para sediar um centro cultural e a Fundação Municipal Cultural Monsenhor Chaves.
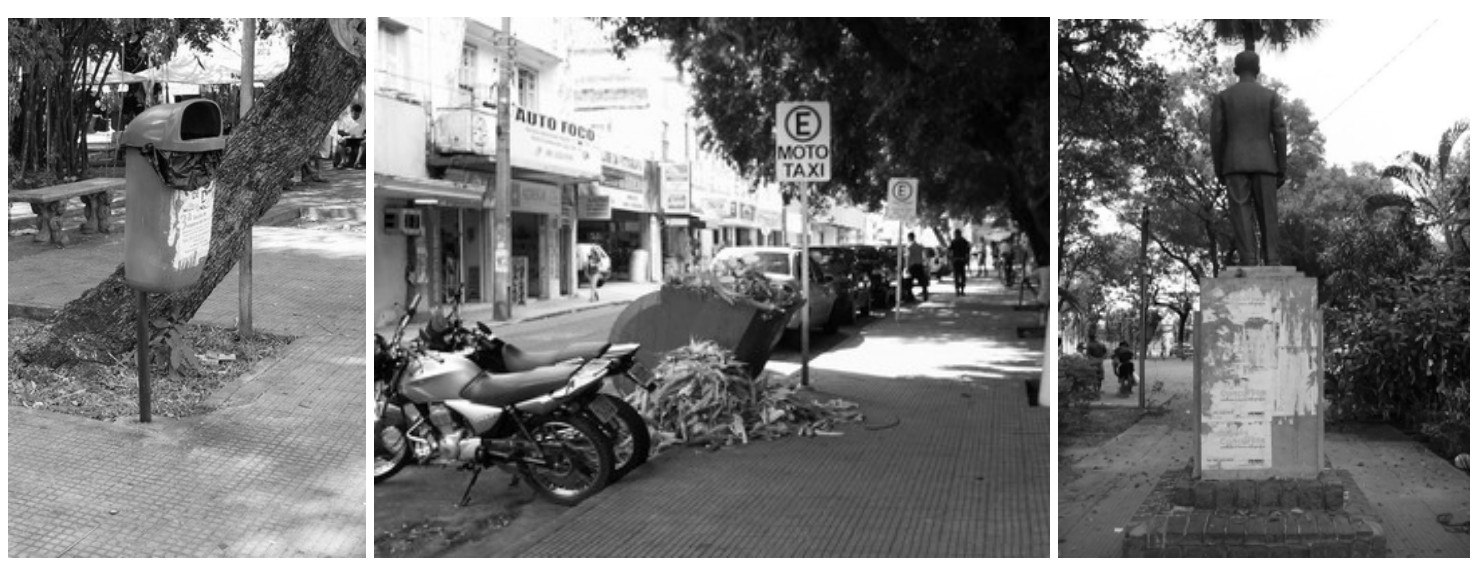

Figura 9 - Lixeira, contêiner e a estátua de Helvídio Nunes na Praça J oão Luis Ferreira 



Figura 10 - Pontos comerciais na Rua David Caldas
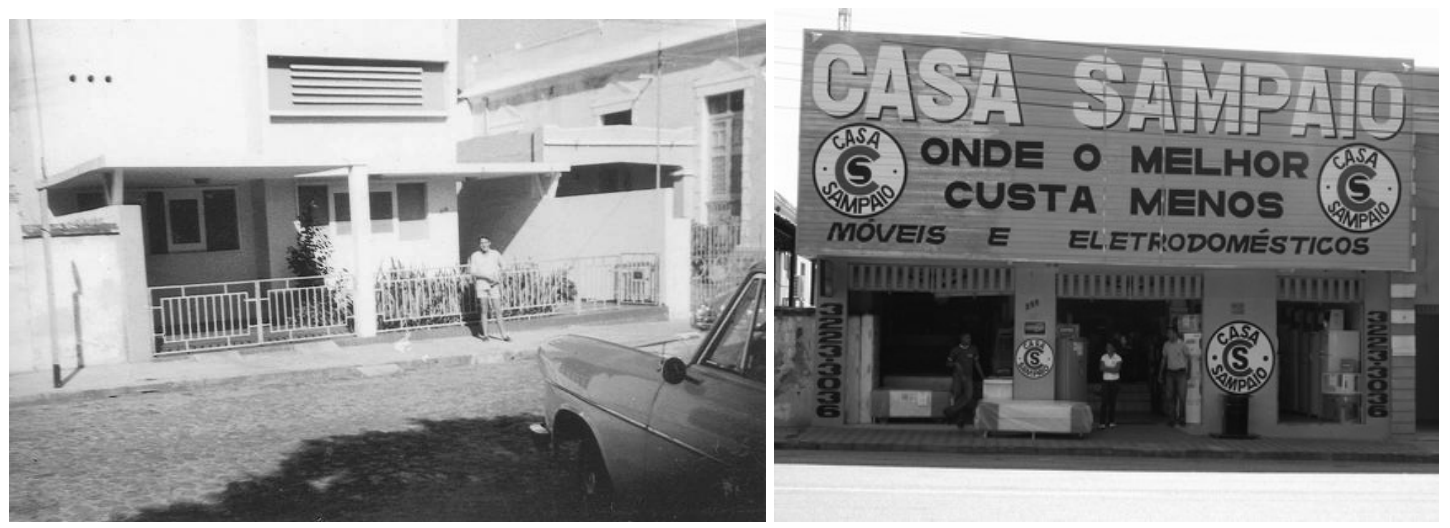

Figura 11 - Casa residencial na década de (a) 1960 em frente à Praça J oão Luis Ferreira e a mesma em (b) 2009

Fonte: (a) acervo de Adriana Fortes e (b) foto de Guilhermina Castro Silva tirada em 2009.


Figura 12 - Casas residenciais na década de 1930 transformadas em pontos comerciais

Fonte: (a) acervo de Maria Lobão, (b) e (d) foto de Guilhermina Castro Silva tirada em 2009 e (c) Gomes (1992, p. 29). 


\section{Usuários e as atividades na Praça J oão Luis Ferreira}

Para identificar a utilização da praça por seus usuários, foram feitas observações no ambiente físico, permitindo estabelecer relações de comportamento dos usuários com esse espaço. O mapa de uso mostra as principais atividades exercidas pelos usuários e a caracterização de seu entorno (Figura 13).

O conhecimento da ocupação das praças em função do tempo é um fator importante na definição de ações do poder público. No presente estudo, observou-se que o fluxo de pessoas é representativo na praça a partir das $7 \mathrm{~h} 00$, com o desembarque dos ônibus, sendo que a maioria apenas passa pela praça, enquanto poucas pessoas permanecem no espaço, para tomar café ou esperar por alguém. Depois das 8 h00, a circulação de transeuntes é maior e contínua, sendo os casais de namorados, comerciantes informais, estudantes e as pessoas que esperam os ônibus os que permanecem por mais tempo.
Em torno das 11h00, o ponto de ônibus fica lotado e a venda de alimentação aumenta, já que algumas pessoas almoçam ou fazem lanches na praça, onde o cardápio é diversificado (Figura 14).

Depois das $14 \mathrm{~h} 00$, o fluxo de pessoas diminui e o espaço mais ocupado é o ponto de ônibus. A partir da $15 \mathrm{~h} 00$, alguns vendedores informais começam deixar o local, e, no final da tarde, poucos se encontram na praça.

Às 17h00, quando os estudantes começam a sair dos colégios, o fluxo de pessoas aumenta e os vendedores de frutas chegam. As lojas comerciais começam a fechar às $18 \mathrm{~h} 00$, fazendo com que o comércio informal aumente as vendas de frutas, bombons, água, refrigerante, batata frita e valetransporte, até às $19 \mathrm{~h} 30$. Às 21h00, os casais de namorados e estudantes que esperam os ônibus são os que mais utilizam a praça, que fica praticamente às escuras, devido às várias lâmpadas queimadas, o que acarreta insegurança.

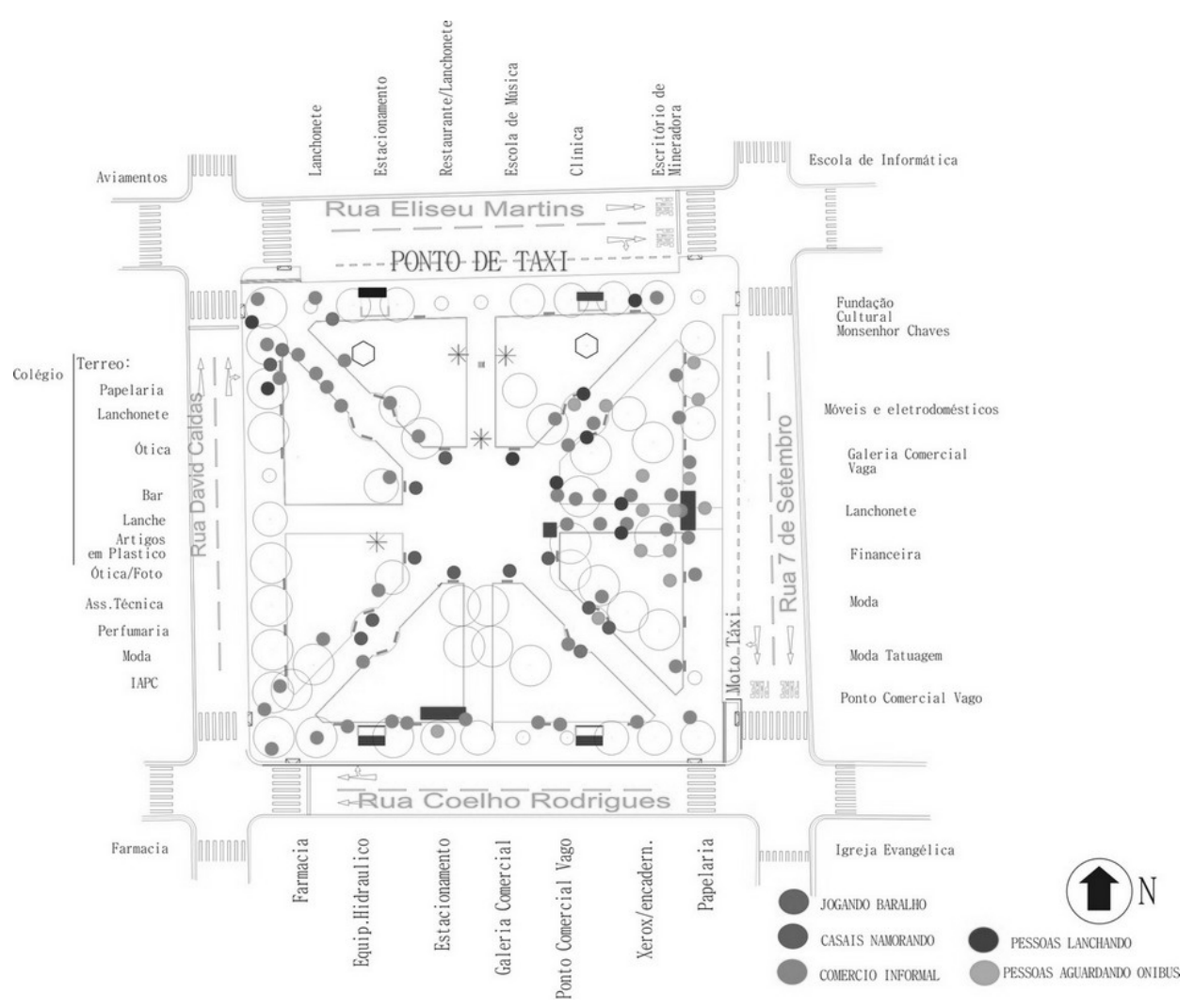

Figura 13 - Mapa de uso da Praça J oão Luis Ferreira 

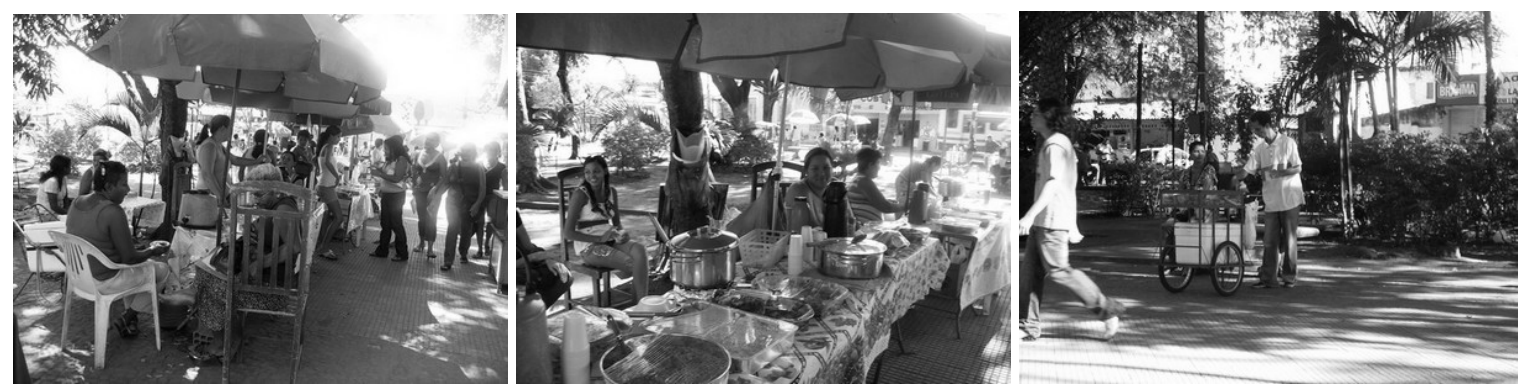

Figura 14 - Vendedores informais que vendem alimentação

Existem dois pontos de comércio que funcionam até as 20h00. No sábado, a partir das $12 \mathrm{~h} 00$, os mesmos comerciantes utilizam o espaço sombreado da praça para colocar cadeiras e mesas. No domingo pela manhã, a praça é utilizada por poucas pessoas, mas é possível encontrar casais de namorados, pessoas esperando pelos ônibus e a presença de vendedores de sorvete/picolé e de vale-transporte.

As principais atividades exercidas atualmente pelos usuários estão relacionadas na Figura 15, destacando-se passar, esperar ônibus e o comércio abrir.

Das principais atividades exercidas pelos usuários, as mais citadas foram esperar ônibus (21,4\%), esperar o comércio abrir ou esperar alguém (22,6\%), e apenas passar (22,6\%), caracterizandose como um espaço de circulação.

A existência dos abrigos de ônibus configura-se como pontos de chegada e saída, atraindo moradores de vários bairros, que se dirigem ao centro da cidade, intensificando o uso do espaço como local de passagem. Observa-se o número significativo de usuários que utiliza o local para encontro, demonstrando que a praça ainda é espaço representativo para os habitantes se reunirem, sendo bastante conhecido na cidade. No caso da Praça João Luis Ferreira, a densa vegetação existente reduz a temperatura, tornando o local agradável.
A Praça João Luis Ferreira, mesmo apresentando alterações profundas na ocupação de seus espaços, ainda funciona como ponto de encontro para os usuários, que se deslocam no centro da cidade para desenvolver suas atividades cotidianas, principalmente durante o dia. Porém, perdeu a função de lazer e de local de referência para atividades culturais e cívicas, que passaram a ser realizadas em outros locais. Isso não é um fato isolado, pois ocorre também em outras cidades do país, devido, entre outros fatores, à atual imagem de insegurança dos espaços urbanos públicos e ao surgimento de outros locais de diversão.

Nas cidades atuais, o shopping center, considerado por Grassiotto e Grassiotto (2003, p. 103), como "[...] um espaço cultural, que absorveu as antigas funções do espaço público, que passaram a acontecer em um espaço fechado, e privado [...]”, substituiu o lazer anteriormente praticado nas praças. Dessa forma, é no shopping que hoje os citadinos desenvolvem atividades outrora relacionadas às praças, como encontrar e fazer amigos, namorar, ver e ser visto, brincar e recrearse, além de ter-se no referido espaço opções de compra, de alimentação, de apresentações musicais e cinemas, sendo atraídos não só pela concentração de atividades como também pela ideia de segurança.

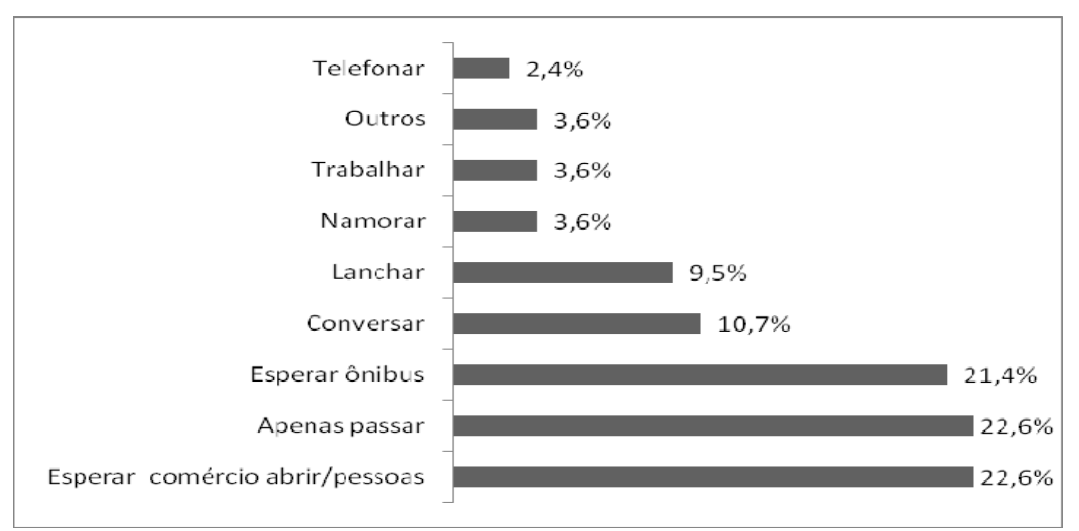

Figura 15 - Atividades realizadas na Praça J oão Luis Ferreira 
Nesse sentido, Mendonça (2007, p. 303) afirma que,

\section{[...] diversões em ambientes fechados $e$ controlados por aparato de segurança $e$ consequentemente seletos e excludentes vem alterando costumes, repercutindo em mudanças nas relações sociais relacionadas aos espaços públicos [...].}

Convém ressaltar, ainda, o surgimento de outro espaço público, característico da sociedade contemporânea, relacionado àquele propiciado pela internet, no qual é possível o contato com amigos, a troca de informações e atividades de recreação, como os jogos on-line, afastando os usuários dos espaços livres.

Essa ideia foi discutida por Gomes (2007, p. 107), que, ao se referir sobre praças públicas, em especial das grandes cidades, afirma que elas perderam,

[...] a atratividade exercida para a população, tendo em vista a disseminação de novos padrões de consumo e lazer representados, sobretudo, pelos shopping centers, pela televisão e, mais recentemente, pela internet [...].

Assim, as transformações observadas na Praça João Luis Ferreira estão relacionadas com as mudanças dos costumes da sociedade, como pode ser observado em outros centros urbanos.

Para Abidin et al. (2010), o desenvolvimento positivo das praças é necessário à participação ativa da comunidade, onde suas necessidades façam parte do programa de revitalização, e que o órgão gestor coordene atrações como eventos e atividades que circundem a área, ou seja, a principal meta das praças é a satisfação e a identificação com esses espaços públicos.

\section{Considerações finais}

A cidade é dinâmica, transformando-se e evoluindo de acordo com as mudanças ocorridas na sociedade, que, consequentemente, se refletem também no espaço público. A praça deixou de ser o lugar das relações sociais por excelência, o espaço principal para o encontro, para manifestações culturais, sociais e políticas, e para o lazer contemplativo e de recreação, sendo substituída por novas maneiras e novos espaços de lazer e de comunicação. A televisão, os jogos de videogame e a internet possibilitam o lazer, a troca de informações, a comunicação virtual globalizada e em tempo real, que promove, inclusive, o encontro e início de amizades, que antes ocorria nos espaços públicos. Além disso, a criação dos shoppings centers, considerados mais seguros e confortáveis, tem contribuído para o esvaziamento dos espaços públicos.

A Praça João Luis Ferreira, inserta inicialmente em bairro residencial e criada com a função de contemplação, recebeu novos usos e novos equipamentos, atendendo às demandas da população. Foi palco de festas comemorativas, local de encontro das famílias e de diversão para as crianças, a partir da introdução do playground. Hoje, constitui-se em espaço caracterizado pelo comércio informal e pela circulação de pedestres, refletindo a característica do entorno, que é basicamente comercial e de prestação de serviços, diferente de sua função inicial, de lazer e de contemplação, reflexo da evolução que ocorreu na sociedade, o que corrobora com a assertiva de que as cidades e seus espaços estão em constante evolução.

Observa-se nesse espaço público o mesmo que ocorre em praças centrais de outras cidades, as quais têm uso intenso durante o dia, caracterizado, principalmente, pelas atividades relacionadas à função de passagem e de prestação de serviços e de comércio, oferecidos no espaço. Porém, à noite, ao se fecharem os estabelecimentos comerciais, tornam-se vazias e pouco usadas, considerando que na região central da maioria de nossas cidades não existe a função habitacional.

Modificou-se a função inicial da Praça João Luis Ferreira, mas o espaço continua vivo, exercendo seu novo papel, adequado às novas demandas da sociedade. Destaca-se, ainda, sua importância como testemunha das transformações e da evolução da cidade e sua representatividade como patrimônio histórico e cultural de Teresina, devendo ser reconhecida pela população e preservada.

As praças, no cotidiano das cidades, continuam sendo espaços de referência. Uma cidade saudável não é apenas um conjunto de edifícios. São os edifícios e espaços públicos da cidade - calçadas, ruas, praças e parques - que garantem "vida” às cidades. Em centros urbanos bem-sucedidos as praças são componentes-chave que compõem o espaço público.

As praças centrais são definidas pelas atividades e utilização diária dos usuários, por isso é importante que em qualquer intervenção feita nesses espaços os moradores e comerciantes da localidade sejam consultados. Assim, garantir-se-á maior sucesso do empreendimento e, consequentemente, ter-se-á a certeza de seu bom uso e funcionamento. Os projetos para revitalização do centro e recuperação das praças centrais valorizam os aspectos do passado como 
um ideal desejado, que, geralmente, entra em conflito com os aspectos da vida moderna, como, por exemplo, a aglomeração de pessoas nas praças devido à colocação de pontos de ônibus, atraindo, assim, o comércio informal, que ocupa indevidamente o espaço da praça e acarreta problemas na estrutura e nos mobiliários e equipamentos existentes na praça.

As políticas públicas urbanísticas devem preservar o patrimônio e melhorar a manutenção da infraestrutura, contemplando a qualidade ambiental, a valorização da paisagem urbana, a melhoria das condições de mobilidade e segurança. Com isso, é reforçada a função de passagem e consumo do centro da cidade, tornando as praças centrais um local de encontro de todos, e o poder público pode, assim, favorecer uma melhor qualidade de vida urbana.

\section{Referências}

ABIDIN, I. Z. et al. Characteristic of Attractive Square as Public Space: Putra square, Putrajaya. In: ANDEA, P.; KILYENI, S. Selected Topics in Energy, Environment, Sustainable Development and Landscaping. Romenia: Politehnica University of Timisoara, 2010. p. 338343.

ALVES, M. R. da S.; LOPES, W. G. R.; SOUSA, G. de B. Apropriação Pelos Usuários de Espaços Públicos: em bairros da zona sul da cidade de Teresina, PI. In: ENCONTRO NACIONAL DE ENSINO DE PAISAGISMO EM ESCOLAS DE ARQUITETURA E URBANISMO NO BRASIL, 7., 2004. Belo Horizonte. Anais... Belo Horizonte: UFMG, 2004.

BARROS, M. V. F.; VIRGÍLIO, H. Praças: espaços verdes na cidade de Londrina. Geografia, v. 12, n. 1, p. 533-544, 2003.

BENÉVOLO, L. História da Cidade. São Paulo: Perspectiva, 2003.

BERTOLUCCI, F. L. A Área Central de Uberlândia: espaço preferencial das atividades informais, os camelôs e os ambulantes. In: SIMPÓSIO REGIONAL DE GEOGRAFIA, 2., 2003, Uberlândia. Anais... Uberlândia: UFU, 2003.

CARVALHO, A. L. P. de. São João de Décadas Passadas em Teresina. Revista Presença, Teresina, v. 20, n. 34, p. 52-53, 2. semestre 2005.
CUNHA, R. D. A. Os Usos, Funções e Tratamentos das Áreas de Lazer da Área Central de Florianópolis. 406 f. Florianópolis, 2002. Tese (Doutorado em Engenharia de Produção) - Universidade Federal de Santa Catarina, Florianópolis, 2002.

DE ANGELIS, B. L. D. et al. Avaliação das Praças de Maringá, Estado do Paraná, Brasil. Acta Scientiarum, Agronomy, Maringá, v. 27, n. 4, p. 629-638, 2005.

DE ANGELIS, B. L. D.; CASTRO, R. M. de; DE ANGELIS NETO, G. Metodologia para Levantamento, Diagnóstico e Avaliação de Praças no Brasil. Engenharia Civil UM, Guimarães, v. 20, n. 1, p. 57-70, 2004.

DOBAL, H. Roteiro Sentimental e Pitoresco de Teresina. Teresina: Fundação Cultural Monsenhor Chaves, 1992.

GOMES, J. A. G. Teresina Ontem e Hoje.

Teresina: Fundação Cultural Monsenhor Chaves, 1992.

GOMES, M. A. S. De Largo a Jardim: praças públicas no Brasil, algumas aproximações.

Estudos Geográficos, Rio Claro, v. 5, n. 1, p. 101120, 2007.

GRASSIOTTO, M. L. F.; GRASSIOTTO, J. de A. A Atividade Comercial e sua Relação com o Urbano: o exemplo de Londrina. Semina:

Ciências Sociais e Humanas, Londrina, v. 24, p. 101-120, set. 2003.

LEFÈBVRE, H. O Direito à Cidade. São Paulo: Centauro, 2001.

LEITÃO, L. (Org.). As Praças Que a Gente Tem, as Praças Que a Gente Quer: manual de procedimentos para intervenção em praças. Recife: Secretaria de Planejamento, Urbanismo e Meio Ambiente, 2002.

LIMA, A. J. de. Favela COHEBE: uma história de luta por Habitação Popular. Teresina: EDUFPI, 1996.

LIMA, S. M. S. A. A Mesma Praça, o Mesmo Banco, as Mesmas Flores, o Mesmo Jardim. Tudo é igual? Transformações no Espaço público: o caso da Praça Pedro II, em Teresina, Piauí. 149 f. Receife, 2001. Dissertação (Mestrado em Desenvolvimento Urbano) - Universidade Federal de Pernambuco, Recife, 2001.

LOW, S. M. Cultura in the Mdern City: the microgeographies of gender, class, and generation in the Costa Rica Plaza. Horizontes

Antropológicos, Porto Alegre, v. 6, n. 13, p. 3164, jun. 2000. 
LOW, S. M. Urban Public Spaces as Representations of Culture: the Plaza in Costa Rica. Environment and behavior, v. 29, n. 1, jan. 1998.

\section{MACEDO, S. S. Quadro do Paisagismo no} Brasil. São Paulo, 1999.

MACEDO, S. S. Espaços Livres. Paisagem Ambiente, São Paulo, n. 7, p. 15-56, jun. 1995

MACEDO, S. S. Os Espaços de Edificação e o Destino da Paisagem Urbana. In: SEMINÁRIO SOBRE DESENHO URBANO NO BRASIL, 2., São Paulo. Anais... São Paulo: Pini, 1986. p. 103110.

MARX, M. Cidade Brasileira. São Paulo: Melhoramentos, 1980.

MELO, E. F. R. Q.; ROMANINI, A. Praça Ernesto Tochetto: importância da sua preservação histórica e aspectos de sua arborização. Revista SBAU, Piracicaba, v. 3, n. 1, p. 54-72, mar. 2008.

MENDONÇA, E. M. S. Apropriações do Espaço Público: alguns conceitos. Estudos e Pesquisas em Psicologia, Rio de Janeiro, v. 7, n. 2, p. 296306, ago. 2007.

MENESES, A. de S.; BEZERRA, D. de O. Edifício do IAPC (INPS): resgate histórico e arquitetônico. In: INSTITUTO CAMILO FILHO.

História da Arte e da Arquitetura no Piauí. Teresina: Instituto Camilo Filho, 2005. p. 55-66.

MONTEIRO, L. R. Relatório da Câmara Municipal de Teresina. Teresina: Graphica Esperança, 1943.

MUMFORD, L. A Cidade na História: suas histórias, transformações e perspectivas. Tradução Neil R. da Silva.São Paulo: Martins Fortes, 1998.

OLIVEIRA, L. A.; MASCARÓ, J. J. Análise da Qualidade de Vida Urbana Sob a Ótica dos Espaços Públicos de Lazer. Ambiente Construído, Porto Alegre, v. 7, n. 2, p. 59-69, abr./jun. 2007.
PINHEIRO, J. de Q.; ELALI, G. A.; FERNANDES, O. S. Observando a Interação Pessoa-Ambiente: vestígios ambientais e mapeamento comportamental. In: PINHEIRO, J. de Q.; GÜNTHER, H. (Org.). Métodos de Pesquisa nos Estudos Pessoa-Ambiente. São Paulo: Casa do Psicólogo, 2008. p. 75-104.

PRAÇAS. Jornal do Piauí, Teresina, 10 nov. 1957. Cidade, p. 2.

REIS, A. T. da L.; LAY, M. C. D. Avaliação da Qualidade de Projetos: uma abordagem perceptiva e cognitiva. Ambiente Construído, Porto Alegre, v.6, n. 3, p. 21-34, jul./set. 2006.

ROBBA, F.; MACEDO, S. S. Praças Brasileiras. São Paulo: Edusp, 2002.

SANTOS, E. S. dos. Reflexões Sobre a Utilização de Espaços Públicos Para o Lazer Esportivo.

RA'EGA, Curitiba, v. 11, p. 25-33, 2006.

SANTOS, L. I. R. Proposta de Um Modelo Conceitual-Teórico Para a Mmanutenção de Praças Públicas no Município de Vitória, ES: estudo de caso. 110 f. Vitória, 2007. Dissertação (Mestrado em Engenharia Civil) - Escola de Engenharia, Universidade Federal do Espírito Santo, Vitória, 2007.

SANTOS, P. Pedala Brasil: saiba o que tem sido feito para dar mais conforto e segurança àqueles que decidem cruzar as cidades de bicicleta. Revista Vida Simples, edição especial Vá de Bicicleta, set. 2008.

\section{SILVA, E. A. Espaços Públicos e}

Territorialidades: as praças do Ferreira, José de Alencar e o Passeio Público, Fortaleza - CE. 164 f. Fortaleza, 2006. Dissertação (Mestrado em Geografia) - Faculdade de Geografia, Universidade Federal do Ceará, Fortaleza, 2006.

TITO FILHO, A. Memorial da Cidade Verde. Teresina: COMEPI, 1978.

Revista Ambiente Construído

Associação Nacional de Tecnologia do Ambiente Construído

Av. Osvaldo Aranha, 99 - 3o andar, Centro

Porto Alegre - RS - Brasil CEP 90035-190

Telefone: +55 (51) 3308-4084 Fax: +55 (51) 3308-4054

www. seer. ufrgs. br/ ambienteconstruido

E-mail: ambienteconstruido@ufrgs.br 